\title{
Behavior of Reinforced Concrete Box Beam Strengthened with CFRP U-Wrap Strips Under Torsion
}

\author{
Shengqiang $\mathrm{Ma}^{1}$, N. Muhamad Bunnori ${ }^{1, \mathrm{a}}$ and K. K. Choong ${ }^{1}$ \\ ${ }^{1}$ School of Civil Engineering, Universiti Sains Malaysia, 14300 Nibong Tebal, Pulau Pinang, Malaysia
}

\begin{abstract}
The present study focuses on the torsional strengthening behavior of reinforced concrete (RC) box section beams that are widely used in bridges. Four RC box beams were fabricated, and three of them were wrapped by carbon fiber-reinforced polymer (CFRP) U-wrap strips with or without longitudinal strips. The different wrapping configuration, cracking angle, failure pattern, and tensile strain of fibers were investigated and discussed accordingly. The experimental results addressed that U-wrap strips strengthening also can upgrade the ultimate torque of beams moderately. In particular, using U-wrap and longitudinal strips to bond the box beams increased the torsional stiffness slightly. The same equation from different codes for calculating RC specimens can accurately predict the ultimate strength of the control beam, but the calculation of the fib model overestimated the torsional strengthening improvement of the wrapped specimens. However, Ghobarah et al. assumed approximately $3000 \mu \varepsilon$ of the average ultimate fiber strain in calculating the ultimate strength of the wrapped box beams which shows in relatively appropriate agreement with testing results.
\end{abstract}

\section{Introduction}

Many structures that have been utilized for years are suffering from accelerated loads, decreased capacity through environmental deterioration and aging, and seismic damage. Strengthening and rehabilitation of the existing structural members would be a cost effectively way with respect to building new structures. Since the past two decades, the materials of fiber-reinforced polymer (FRP) have gradually replaced steel plates to be used in retrofitting reinforced concrete (RC) members. As strengthening materials, the merits of FRP are distinct that they have high tensile strength, lightweight, corrosion immunity, being shaped easily, and high fatigue strength. Although FRP strengthening technique already has been used in upgrading the strength of structures such as buildings and bridges [1], more research work still exists to be studied for further comprehending the behavior of strengthened structures.

Most researchers have paid much attention to flexural and shear strengthening beams bonded with FRP by experimental and numerical studies[2-4], and the investigated achievements have made significant progress. However, few types of research were involved in the torsional behavior of the beams strengthened with FRP. From the present century, Zhang et al. [5] and Ghobarah et al. [6] conducted preliminary and exploratory studies on the torsional strengthening behavior of RC members bonded with FRP. The two experimental investigations showed the ductility and torsional strength of

\footnotetext{
${ }^{a}$ Corresponding author : cenorazura@usm.my
} 
the strengthened RC rectangular specimens with FRP increased reasonably. The researchers [7-9] did not only perform a torsional test on rectangular beams strengthened with carbon fiber-reinforced polymer (CFRP) and glass fiber-reinforced polymer GFRP but also proposed an analytical method for calculating ultimate torque of strengthened RC specimens. The experimental study proved that the ductility of all strengthened torsional specimens increased, but the level of increment based on the configuration of FRP. The authors suggested that compressive strength of confined concrete should be applied in the proposed model to calculate the ultimate torsional strength more accurately. Hii and AlMahaidi [10-12] focused on the experimental and numerical studies of the box and solid cross section RC beams bonded with FRP; the testing results showed an increase in percentage of solid section beam was more than that of the box section beam. Chalioris [13,14] conducted the experimental study on rectangular and T-beams strengthened with CFRP subjected to torsion; the testing investigation displayed that complete wrapping with continuous sheets was more efficient than the same volume of strips in the torsional strengthening rectangular members, and a limited increase in torsional strength appeared in the T-beams with U-wrap. Thus, the author suggested that rational anchor should be used in T-beams with U-wrap for improving the strengthening effectiveness. In practical projects, it is impossible to access the entire cross section of a beam by fully wrapping due to the presence of the surface of the floor slab or bridge deck $[6,15]$.

Box section beams are widely used in bridges that are also suffering the problems mentioned above and need to be retrofitted. Few studies have been paid attention to the torsional behavior of RC box beams strengthened with FRP. Therefore, in the current experimental study, CFRP U-wrap strips with or without longitudinal strips were applied in torsional strengthening RC box beams due to inaccessibility of the top face of beam; the objective is to investigate and to evaluate effectiveness of strengthening configuration, failure patterns, twist angle, and fiber strain of the retrofitted box beams .

\section{Experimental Programs}

Four scaled RC box beams with $350 \mathrm{~mm}$ x $400 \mathrm{~mm}$ hollow cross-section and 2,000 $\mathrm{mm}$ length were cast for a torsional test. Three specimens were externally bonded with CFRP and one specimen was a control beam.

\subsection{Materials}

The concrete compressive strength obtained by testing cubes cured for 28 days is shown in Table 1 . The yield strength of stirrups R6 and R8 was 372 and $472 \mathrm{MPa}$, respectively. The yield strength of the top longitudinal bar R10 and bottom bar T16 was 466 and $547 \mathrm{MPa}$. CFRP had a tensile strength of $4,900 \mathrm{MPa}$, modulus of elasticity of $230 \mathrm{GPa}$, the thickness of $0.117 \mathrm{~mm}$, and an ultimate elongation of $1.8 \%$.

\subsection{Test setup}

Special equipment was designed in the torsional experiment. Two fabricated steel end supports were installed on two steel walls, separately. One end of the specimen was fixed in a supportive collar to avoid longitudinal, transverse, and rotational actions. Another supportive collar was designed to twist freely through a rotational shaft whose base was fixed on the steel wall. A rotational cell of $400 \mathrm{kN}$ capacity hydraulic actuator was placed to load on the top of the rotational support of $150 \mathrm{~mm}$ perpendicular distance from the loading position to the horizontal center line of the box beam.

\subsection{Specimen characteristics}

The box beam was 2,000 $\mathrm{mm}$ long, $400 \mathrm{~mm}$ wide and $350 \mathrm{~mm}$ high. The width of the two sides' web and the top thickness were all $50 \mathrm{~mm}$, and the thickness of the bottom was $60 \mathrm{~mm}$. The longitudinal 
reinforcement bars 4T16 and 3R10 were applied on the bottom and top flange, separately. Apart from the $150 \mathrm{~mm}$ range of two ends, $6 \mathrm{~mm}$ diameter internal steel stirrups were placed to the whole span at a center to center with the spacing of $100 \mathrm{~mm}$. Two tips were designed to be reinforced with the $8 \mathrm{~mm}$ diameter internal transverse steel with a center to center with spacing of $50 \mathrm{~mm}$ to avoid two supportive ends failure prematurely. The details on the dimensions and reinforcement arrangement of the box beams are presented in Figure 1.

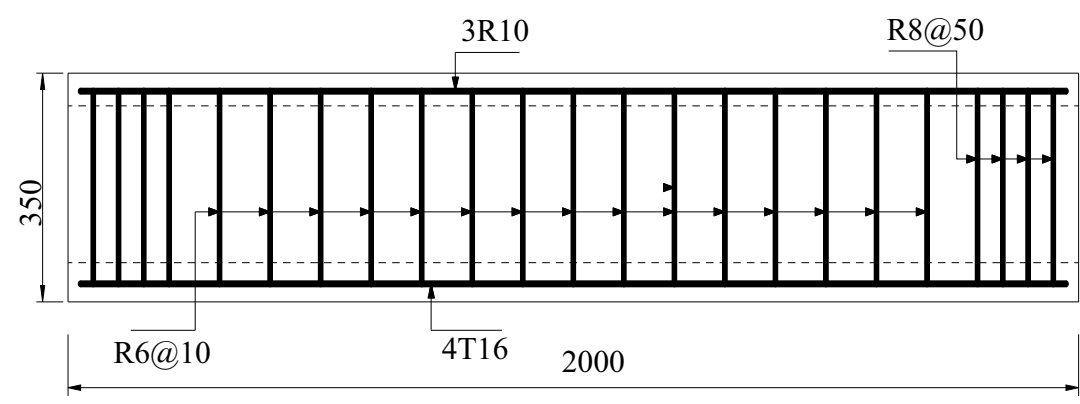

(a)

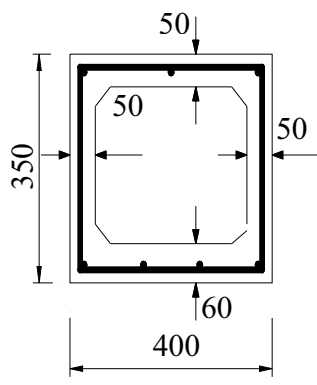

(b)

Figure 1. Details on the dimensions and reinforcement arrangement of the box beam: (a) Longitudinal section and (b) Cross section (all dimensions in $\mathrm{mm}$ ).

\subsection{CFRP strengthening configuration}

Two webs and the bottom of the beams were strengthened by $100 \mathrm{~mm}$ CFRP U-jacketing strips at a center to center of $200 \mathrm{~mm}$ spacing along the length of the beams. TBS was only strengthened by onelayer of U-jacketing strips. TBSL1 and TBSL2, however, were wrapped with one and two-layer Ujacketing strips with one-layer longitudinal strips that were used to suppress the ends of U-jacketing to supply nondestructive anchorage. CFRP strengthening configuration is illustrated in Figure 2.
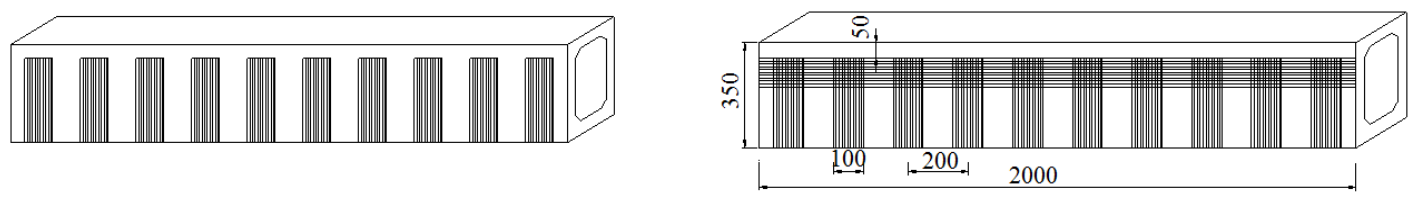

Figure 2. Schematic of the strengthened box beams: (a) wrapped in one-layer strips (TBS), (b) wrapped in onelayer strips with one-layer longitudinal strip (TBSL1) and (c) wrapped in two-layer strips with one-layer longitudinal strip (TBSL2 ) (all dimensions in mm).

\subsection{Instrumentation}

The setup of the test instrumentation is presented in Figure 3. A load cell was placed on the top of the rotational end, and the applied load provided by a hydraulic actuator was recorded by a computercontrolled data acquisition system at approximately $5.0 \mathrm{kN}$ loading intervals loaded manually. Two linear variable displacement transducers (LVDTs) were installed at the bottom of the rotational end to calculate the twist angle at every loading level. Out of the five strain gauges, two separate ones were located on the surfaces of CFRP $700 \mathrm{~mm}$ and $1200 \mathrm{~mm}$ of distance from the rotational end, whereas the others were placed in the same longitudinal location at $900 \mathrm{~mm}$ of distance from the rotational end and distributed vertically. 


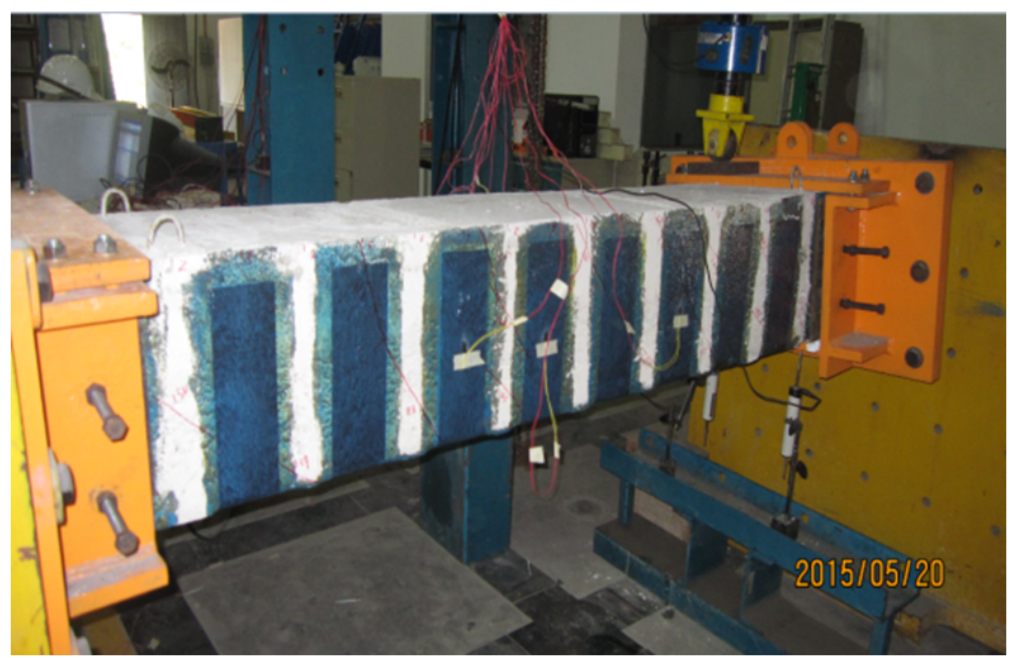

Figure 3. Photograph of the instrument.

\section{Experimental Results}

The cracking torque, ultimate torque, and twist angle at cracking and ultimate load for all the tested beams are illustrated in Table 1.

Table 1(a). Cracking, ultimate torque, and twist angle of box beams.

\begin{tabular}{|c|c|c|c|c|c|c|}
\hline Beam & $\begin{array}{c}\text { Concrete } \\
\text { compressive } \\
\text { strength (MPa) }\end{array}$ & $\begin{array}{c}\text { Cracking } \\
\text { torque } \\
T_{\text {cr }} \text { (kN.m) }\end{array}$ & $\begin{array}{c}\text { Increase } \\
\text { in } \\
T_{\text {cr }}(\%)\end{array}$ & $\begin{array}{c}\text { Twist angle } \\
\text { at cracking } \\
\text { torque }\left(^{\circ}\right)\end{array}$ & $\begin{array}{c}\text { Ultimate } \\
\text { torque } \\
T_{u} \text { (kN.m) }\end{array}$ & $\begin{array}{c}\text { Increase } \\
\text { in } \\
T_{u}(\%)\end{array}$ \\
\hline TBC & 38.87 & 10.29 & & 0.25 & 22.88 & - \\
\hline TBS & 40.37 & 10.25 & -0.4 & 0.4 & 26.67 & 16.6 \\
\hline TBSL1 & 35.03 & 12.53 & 21.7 & 0.45 & 26.52 & 15.9 \\
\hline TBSL2 & 37.57 & 12 & 16.6 & 0.26 & 27.56 & 20.5 \\
\hline
\end{tabular}

Table 1(b). Cracking, ultimate torque, and twist angle of box beams.

\begin{tabular}{cccccc}
\hline Beam & $\begin{array}{c}\text { Twist angle at } \\
\text { ultimate torque } \\
\left({ }^{\circ}\right)\end{array}$ & $\begin{array}{c}\text { Increase in } \\
\text { torsional } \\
\text { stiffness }(\%)\end{array}$ & $\begin{array}{c}\text { Calculate } \\
\text { ultimate torque } \\
\mathbf{T}_{\mathbf{u c}}(\mathbf{k N . m})\end{array}$ & $\begin{array}{c}\mathbf{T}_{\mathbf{u}} / \mathbf{T}_{\mathbf{u}} \text { cal } \\
(\boldsymbol{f i b})\end{array}$ & $\begin{array}{c}\mathbf{T}_{\mathbf{u}} / \mathbf{T}_{\mathbf{u} \text { cal }} \\
(\mathbf{G h o b a r a h})\end{array}$ \\
\hline TBC & 2.47 & - & 22.7 & 1.01 & - \\
TBS & 2.85 & 1 & 35.99 & 0.735 & 0.940 \\
TBSL1 & 2.71 & 5.6 & 35.6 & 0.745 & 0.934 \\
TBSL2 & 2.83 & 5.1 & 40.6 & 0.678 & 0.810 \\
\hline
\end{tabular}

The curve of the torsional moment versus twist angle of all box beams is drawn in Figure 4. As expected, the ultimate strength of strengthened box beams increases noticeably compared to the control beam TBC. Among all the strengthened beams, TBSL2 wrapped by two-layer U-wrap strips with one-layer longitudinal strip increasing $20.5 \%$ has the best strengthening effectiveness at ultimate strength. The maximum increases in cracking torque, $21.7 \%$ and $16.6 \%$, are for TBSL1 and TBSL2, 
which have longitudinal strips bonding over the transverse strips to resist cracks generating. The TBS only with U-wrap strips, however, showed the poorest value at cracking toque. It is an interesting point that the ultimate torque and ultimate twist angle of TBSL1 is slightly lower than that of TBS, which may be explained that the compressive strength of concrete of TBS is higher than the value of TBSL1. It is evidently found that the rise of twist angles is from all strengthened beams, and the torsional stiffness of strengthened box beams showed slight increase, $1 \%$ for TBC, $5.6 \%$ for TBSL1, and $5.1 \%$ for TBSL2.

From the results of the torsional stiffness, CFRP longitudinal strips suppressing transverse strips played a particular action in improving the torsional stiffness of box beams corresponding ultimate torque increasing $15.9 \%$ for TBSL1 and $20.9 \%$ for TBSL2, respectively. Although TBSL2 with twolayer strips has better strengthening behavior than TBSL1 with the one-layer strip, there is no proportional relationship between the layers and the ultimate strength. It can be seen from Figure 4 that the trend of the torque-twist angle of all beams has not much difference before cracking. In the post-cracking phase, all the curves had a gentle slope to reach the peak torque of beams due to stirrup or stirrup with CFRP strips resisting the torque loaded on the beams. Due to torsional stiffness without remarkable increase, the loading would stop immediately after reaching the peak torque.

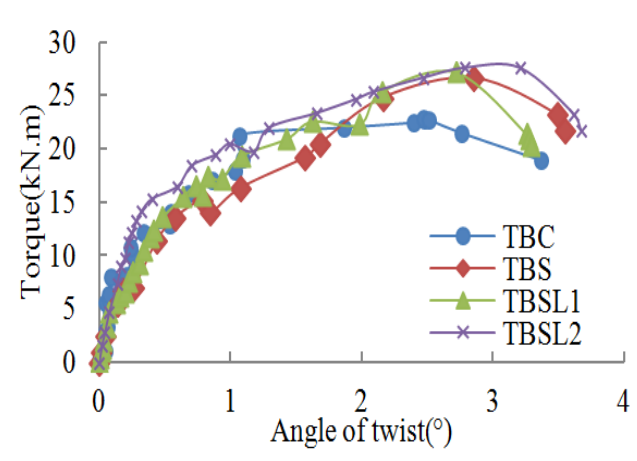

Figure 4. Curve of torque versus twist angle.

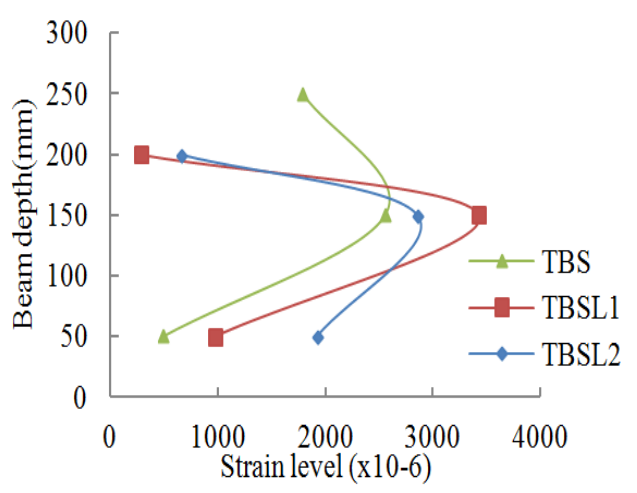

Figure 5. Strain development along depth of beam at ultimate torque.

From Figure 6, the control box beam TBC exhibited typical torsional failure pattern with one widened the inclined spiral crack. Three bonded beams performed different failure patterns. At a high load level, failure of TBS occurred through debonding of the CFRP strips with a wide crack in one strip. To TBSL1 and TBSL2 with CFRP transverse and longitudinal strips, the failure mechanism showed the longitudinal strip rupture that provided physical anchorage to prevent transverse strips debonding. From the investigation in experiment, the primary cracking angles of all beams fluctuated around $45^{\circ}$ with respect to the longitudinal axis of beams whereas all the angles varied between $35^{\circ}$ and $55^{\circ}$, which is in line with the angle of diagonal crack assumption in fib [16]. The distribution of many minor cracks in the unwrapped spacing of strengthened beams was more uniform than that of control beam failed in one main crack. CFRP strips helped distribute the stress along the whole beam of concrete.

Strain gauges were stuck on strips along the depth of each beam to get the strain condition. The even strain of each strengthened box beam versus beam depth is plotted in Figure 5. The general trend of three curves is like a parabola and the maximum strain is less than $3500 \mu \varepsilon$ at a point near the neutral axis of the beam. The strain of two beams strengthened with CFRP strips and longitudinal strips is higher than TBS only strengthened with transverse strips due to longitudinal strips confining. It also can be discovered from Figure 6 that the strain of TBSL2 is lower than that of TBSL1 despite the same strengthening configuration with different transverse strips plies. It may be considered that rigidity of two layers is greater than that of one layer at approximately the same stress which can be concluded from the ultimate torque. 

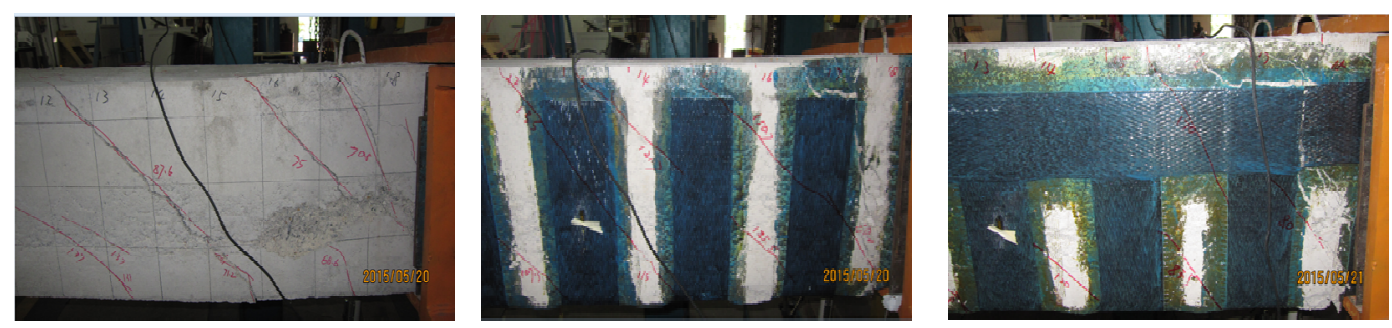

Figure 6. Failure patterns of the specimens: (a) TBC, (b) TBS, and (c) TBSL1 and TBSL2.

\section{Analysis}

$\mathrm{fib}$ model [16] is an available model in predicting the ultimate torque of FRP contribution, which was calculated as follows:

$$
\begin{gathered}
T_{f}=E_{f} \varepsilon_{f e} t_{f} w_{f} b h \cot (\theta) / s_{f} \\
\varepsilon_{f e}=\min \left[0.17\left(\frac{f_{c}^{2 / 3}}{E_{f} \rho_{f}}\right)^{0.3} \varepsilon_{f u}, 0.65\left(\frac{f_{c}^{2 / 3}}{E_{f} \rho_{f}}\right)^{0.56} \times 10^{-3}\right]
\end{gathered}
$$

where $E_{f}$ is Young's modulus of the FRP; $\varepsilon_{f e}$ is the effective strain in the fiber; $t_{f}$ is the thickness of FRP; $S_{f}$ is the spacing of FRP strips; $w_{f}$ is the width of FRP; $b$ and $h$ are the width and height of beam; $\theta$ is the diagonal angle of crack; $f_{c}$ is the concrete compressive strength; $\rho_{f}=2 t_{f} w_{f} / b S_{f}$ which is FRP reinforcement ratio. Assuming there is no interaction between the internal stirrup and the external FRP strips, the total torque $\left(T_{u}\right)$ of the strengthened RC beam can be calculated by: $T_{u}=T_{u c}+T_{f}$. Equation (3) of the ultimate torque is adopted in the ACI318 [17], Australian code [18], and BS8110-2 [19] detailed as:

$$
T_{u c}=2 A_{0} A_{t} f_{y t} \cot \theta / s_{t}
$$

where $A_{0}$ is the gross area enclosed by shear flow path and is taken as $0.85 A_{0 h}$, where $A_{0 h}$ is the area enclosed inside the hoops; $A_{t}$ is the area of transverse reinforcement; $f_{y v}$ is the yield strength of transverse reinforcement; $S_{t}$ is the spacing of stirrups.

The computed ultimate torque using fib model [16] was compared to the experimental results as shown in Table.1. In the calculation $\theta$ was taken at $45^{\circ}$ not only by the angle measured in the experiment but also with the angle provided by $f i b$ model[16]. From the table, the adopted RC beam model can accurately predict the ultimate torque of the control beam; but the addition of Equation (1) and Equation (3) over-estimated the ultimate torque of the strengthened beams because the calculated strain of fiber was higher than the experimental results. Ghobarah et al. [6] considered that the average ultimate fiber strain can be assumed approximately $3000 \mu \varepsilon$; thus for U-jacketing wrapping

$$
T_{f}=0.003 E_{f} t_{f} w_{f} b h / s_{f}
$$

The ultimate torsional moment of the strengthened beams calculated by Equation (4) shows in relatively good agreement with testing results which is also listed in Table 1. 


\section{Summary}

Three box beams strengthened by CFRP U-wrap strips with or without longitudinal strips were investigated that the ultimate torque increased moderately with respect to the control beam. The increasing percentage of the ultimate torque was $16.6 \%$ for TBS, $15.9 \%$ for TBSL1, and $20.5 \%$ for TBSL2. The beam strengthened with two-layer U-wrap strips and longitudinal strips showed the best improvement. Among of three strengthened beams, TBSL1 and TBSL2 with longitudinal strips showed slightly increase in the torsional stiffness of box beams and also increase in the cracking torque. The two typical failure patterns were observed in the experiment. At a high load level, failure of beam strengthened U-wrap strips was debonding of the strips with a wide crack, but the failure mechanism of beams strengthened with transverse and longitudinal strips showed the longitudinal strip rupture that may provide physical anchorage to avoid the debonding of the transverse strips. The experimental results of diagonal cracks also displayed that the angles mostly fluctuated at around the angle of $45^{\circ}$ with the longitudinal axis of beams thus validating the value proposed in the $f i b$ model[16]. The maximum strain of fiber was less than $3500 \mu \varepsilon$ and located around the neutral axis of the beam. The ultimate torque of the wrapped beams computed by the fib model is higher than the experimental results. However, the computational values using the model proposed by Ghobarah et al. [6] are considerably close to the experimental results.

\section{References}

[1] T. Gosbell and R. Meggs, West Gate bridge approach spans FRP strengthening Melbourne, Australia, IABSE Symposium Report, International Association for Bridge and Structural Engineering, 55-60, (2002).

[2] T.C Triantafillou and C.P. Antonopoulos, Design of concrete flexural members strengthened in shear with FRP, J. of Composites for Construction, 4(4), 198-205, (2000).

[3] D. Kachlakev and D.D. McCurry, Behavior of full-scale reinforced concrete beams retrofitted for shear and flexural with FRP laminates, Composites Part B: Engineering, 31(6-7), 445-452, (2000).

[4] J. Dong, Q. Wang and Z. Guan, Structural behaviour of RC beams with external flexural and flexural-shear strengthening by FRP sheets, Composites Part B: Engineering, 44(1), 604-612, (2013).

[5] J.W. Zhang, Z.T. Lu and H. Zhu, Experimental study on the behaviour of RC torsional members externally bonded with CFRP, Proc. of the Int. Conf. on FRP Composites in Civil Engineering, 1, 713-722, (2001).

[6] A. Ghobarah, M. Ghorbel and S. Chidiac, Upgrading torsional resistance of reinforced concrete beams using fiber-reinforced polymer, J. of Composites for Construction, 6(4), 257-263, (2002).

[7] M. Ameli, H.R. Ronagh, M.A. Bradforf and B. Uy, Numerical predictions for the ultimate torque capacity of FRP strengthened reinforced concrete beams, Proc. of FRP Composites in Civil Engineering, Balkema, 579-585, (2005).

[8] M. Ameli and H.R. Ronagh, Analytical method for evaluating ultimate torque of FRP strengthened reinforced concrete beams, J. of Composites for Construction, 11, 384-390, (2007).

[9] M. Ameli, H.R. Ronagh and P.F. Dux, Behavior of FRP strengthened reinforced concrete beams under torsion, J. of Composites for Construction, 11, 192-200, (2007).

[10] A.K. Hii and R. Al-Mahaidi, Experimental investigation on torsional behavior of solid and boxsection RC beams strengthened with CFRP using photogrammetry, J. of Composites for Construction, 10, 321-329, (2006).

[11]R. Al-Mahaidi and A.K. Hii, Bond behaviour of CFRP reinforcement for torsional strengthening of solid and box-section RC beams, Composites Part B: Engineering, 38, 720-731, (2007).

[12]A.K. Hii and R. Al-Mahaidi, Torsional capacity of CFRP strengthened reinforced concrete beams, J. of Composites for Construction, 11, 71-80, (2007). 
[13]C.E. Chalioris, Behavioural model of FRP strengthened reinforced concrete beams under torsion, Asia-Pacific Conf. on FRP in Structures, Hong Kong, (2007).

[14]C.E Chalioris, Torsional strengthening of rectangular and flanged beams using carbon fibrereinforced-polymers-experimental study, Construction and Building Materials, 22(1), 21-29, (2008).

[15]A. Deifalla and A. Ghobarah, Strengthening RC T-beams subjected to combined torsion and shear using FRP fabrics-experimental study, J. of Composites for Construction, 14, 301-311, (2010).

[16] fib Bulletin 14, Externally Bonded FRP Reinforcement for RC Structures, Lausanne, (2001).

[17]ACI 318-08, Building Code Requirements for Structural Concrete and Commentary, American Concrete Institute, Michigan, (2010).

[18]Australian Standard, Concrete Structures, Standards Association of Australia, Sydney, (2009).

[19]BS 8110, Structural Use of Concrete Part 2, Code of Practice for Special Circumstances, British Standards Institution, London, (1985). 